\title{
EXAMINING PRISON RULE VIOLATIONS AMONG INCARCERATED VETERANS WITH A HISTORY OF BRAIN INJURY, ALCOHOL, AND SUBSTANCE USE
}

\author{
Sriram Chintakrindi \\ California State University, Stanislaus \\ E-mail: schintakrindi@csustan.edu \\ Suditi Gupta \\ California State University, Stanislaus, Modesto Junior College
}

\begin{abstract}
Background: To investigate how the independent variables: veteran status, brain injury, drug use, and alcohol use predict risk for rule violations and assaulting jail or prison staff while incarcerated. This study used aggregated and disaggregated data to demonstrate relationships between exposure and outcomes.

Methods: Cross-sectional survey data was collected from the Survey of Inmates in State and Federal Correctional Facilities (SISFCF), 2004 ( $n=14499)$. Chi-square, Cochran-Mantel-Haenszel $(C M H)$, and logistic regression were conducted to determine the relative contribution of the independent variables in predicting rule violations and assaulting jail or prison staff while incarcerated. The research study tested a number of hypotheses that are listed in the hypotheses section of the research study.

Results: The findings from the logistic regression conducted in this study demonstrate a significant relationship between veteran status, alcohol use, and brain injury status and the dependent variable: found guilty or written up for jail or prison rule violations while incarcerated.

Conclusion: Alcohol use and brain injury present serious risks for maintaining public health and safety of incarcerated veterans and non-veterans. Daily or almost daily consumption of alcohol was the strongest predictor of jail or prison rule violations. Therefore, researchers and practitioners should continue to develop interventions and policies for reducing alcohol consumption of individuals in contact with the criminal justice system.
\end{abstract}

Keywords: veteran effect, brain injury, assault, substance use

\section{INTRODUCTION}

As wars in the Middle East come to a conclusion and military service members and veterans of the United States armed forces are relocated back to their communities and families, researchers have noted that veterans are at increased risk of experiencing issues related to physical health, mental health, alcohol, and substance abuse that can lead to involvement with the criminal justice 
system (Russell, 2009; Greenberg and Rosenheck, 2011). Greenberg and Rosenheck (2011) note that one of the negative outcomes of military service for veterans exposed to combat compared with civilians includes increased risk for incarceration as a result of veterans experiencing elevated rates of post-traumatic stress disorder (PTSD), substance abuse, neurological disorders, and psychiatric disorders (p. 2).

Cote et al. (2020) examined the unique demographic factors of inmates with veteran status and found that the mean age of veterans at the time of their arrest was 35. Cote et al. (2020) state that inmates with veteran status have unique criminogenic risk factors that included: "prior criminal convictions (72\%), mental health conditions (72\%), homelessness (24\%), and alcohol and substance abuse (88\% and 64\%, respectively)." However, there are gaps in the existing literature in terms of exploring the relationship between veterans with histories of brain injury, drug use, and alcohol use and how those inmates adhere to jail or prison rules while incarcerated. Additionally, one of the aims of the study is to help us understand whether histories of brain injury, drug use, and alcohol use among incarcerated veterans is a risk factor for inmates assaulting staff and correctional officers.

\section{LITERATURE REVIEW}

Logan, McNeeley, \& Morgan (2021b) describe the "veteran effect" as a perspective that assumes that military careers can have residual and long lasting "deleterious and brutalizing effects" on service members and veterans, which can result in recidivism, aggression, and violent behavior higher than average compared with the general population. Furthermore, military veterans possess unique criminogenic risk factors, such as traumatic brain injury (TBI), post-traumatic stress disorder (PTSD), personality disorders, substance use, homelessness, family dysfunction, and mental health issues. However, they found no results to support the "veteran effect" perspective after examining the prevalence of theoretically relevant variables between incarcerated veterans and non-veterans when measuring institutional adjustment and recidivism rates.

Logan, McNeeley, \& Morgan (2021a) found that the effects of TBI, PTSD, and other criminogenic risk factors were observable when examining the experiences of military veterans involved in the criminal justice system, especially when measuring recidivism rates. More specifically, they found that both TBI and PTSD were predictive of recidivism, including re-arrest, revocation, and re-conviction. However, they did not find that TBI or PTSD were significantly related to the risk of being sentenced to extended segregation for engaging in misconduct, such as drug use, smuggling contraband, or attempting to escape.

Previous research has found that veterans that have served in an all-volunteer force (AVF) in Iraq and Afghanistan after 2001 are more likely to be incarcerated than their non-veteran peers (Black, 2005; Davis et al., 2003; Moses, 2009, Saxon et al., 2001; Greenberg \& Rosenheck, 2009). Previous research has also found that Vietnam era veterans that were forced to join the military due to drafting policies did not have a higher risk of being incarcerated compared with their non-veteran peers (Greenberg and Rosenheck, 2011). Greenberg and Rosenheck (2011) state that the differences in risk for incarceration between the AVF and Vietnam era veterans can be explained by variations in patterns of recruiting and standards for maintaining the ranks rather than variations 
in exposure to combat (p. 14). Individuals that voluntarily join the armed forces possess different personality, socio-economic, political, and educational characteristics compared with individuals who are drafted into the armed forces. However, Greenberg and Rosenheck (2011) do not discuss how drug use and alcohol use rates vary between AVF, drafted personnel, and non-veteran peers. These difference may also contribute to risk for incarceration and risk for rule violations and violence while incarcerated.

Greenberg and Rosenheck (2011) conducted logistic regressions and found that the odds of being incarcerated in jail for veterans with a high school diploma or GED were $410 \%$ higher compared with individuals with higher levels of education. The researchers also found that the odds of being incarcerated in jail for veterans that reported being abused as a child were $110 \%$ higher than for incarcerated veterans who did not report being abused as a child (p. 13). Greenberg and Rosenheck (2011) also conducted logistic regressions and found that the odds of being incarcerated in state and federal prison for veterans that were diagnosed with mental health issues were $29 \%$ higher than for incarcerated veterans with no reported mental health issues (p. 13). Also the odds for state and federal prisoners with veteran status being incarcerated that had a stay in an overnight hospital for mental health issues prior to incarceration were $37 \%$ higher compared with incarcerated veterans with no history of staying in a mental health hospital (Greenberg and Rosenheck, 2011). These findings strongly indicate that jail and prison inmates with veteran status have substantial histories of mental health and trauma prior to being incarcerated. Greenberg and Rosenheck (2011) also found that the odds of veterans incarcerated in jail that had been attacked with a knife prior to incarceration were $60 \%$ higher than for veterans that were incarcerated in jail that had not reported any knife attacks. This finding also indicates that veterans in jail are at high risk of encountering violent confrontations inside and outside of jail. These findings may suggest that veteran status inmates with mental health or brain injury are also at risk of jail or prison rule violations and violently attacking jail or prison staff.

A report released in September 2012 by the Institute of Medicine (IOM) and funded by the Department of Defense (DOD) reveals how the present military culture among military physicians has enabled active military duty personnel to obtain 3.8 million prescriptions for painkillers in 2009 (IOM and DOD, 2012). The report reveals that in 2002 only 3 percent of veterans admitted to "any illicit drug use, including prescription drug misuse". However, by 2008, 12 percent of active military personnel admitted to "any illicit drug use, including prescription drug misuse". The report also describes how about 20 percent of active military personnel who were surveyed in 2008 indicated that they drank at least five or more drinks at least once a week which was also considered binge drinking (IOM and DOD, 2012). Logistic regressions conducted by the IOM and DOD (2012) reveal that the odds of Marine Corps personnel engaging in heavy alcohol use are $84 \%$ higher compared with Air Force personnel (p. 2-16). Logistic regressions also reveal that the odds of Army personnel engaging in illicit drug use and misuse are $121 \%$ higher compared with Air Force personnel (IOM and DOD, 2012). Twenty-six percent of all members of military forces (Army, Navy, Marine Corps, and Air Force) aged 18-25 were engaged in "heavy alcohol use" compared with 16 percent of the civilian population between 18 and 25 years of age. These findings point to the culture within the armed forces of heavily engaging in alcohol and prescription drug abuse, especially among forces (Army and Marines) that are actively training and engaging in ground combat. Although 
the report provides a single case study of a soldier that was arrested for alcohol and drug abuse related incidents, it fails to elaborate on the overall rates of incarceration of AVF veterans and their adherence to jail or prison rules while incarcerated. The failure to investigate and report the collateral consequences of soldiers' alcohol and drug abuse may highlight continued gaps in the military's understanding of how the interaction of neurological, psychiatric, and substance abuse issues can result in incarceration for military personnel returning to civilian life.

Although a large body of literature exists concerning veterans and their risk for psychiatric, neurological, and substance abuse issues after experiencing combat, there is little research on the experiences of veterans that fail to reintegrate into society and their risk for incarceration or committing suicide while incarcerated. Wortzel et al. (2009) state that "few outcomes represent a greater failure at reintegration in civilian life among our veterans than suicide" (p. 82). It has been shown that the interaction of being a veteran and becoming incarcerated increases the risk for suicide. Wortzel et al. (2009) reviewed a research study which analyzed the cause of death of 1075 veterans and found that the veteran suicide rate was two to three times that of the general population (p. 83). The researchers also report data presented by the Bureau of Justice Statistics that indicates that the 2002 suicide rate in jails was 47 per 100,000, and in prisons it was 14 per 100,000 (Wortzel et al., 2009). Wortzel et al. (2009) also reported that males were 56 percent more likely to commit suicide while incarcerated than females (p. 85). The researchers discuss how the closure of beds and diminished funding within the Veterans Association (VA) healthcare system has not displaced the supervision of veterans from clinical facilities to the criminal justice system. However, $39.6 \%$ of male users of the VA system between the ages of 18 to 39 were incarcerated between 1994 and 1997 (Wortzel et al., 2009). This finding highlights the overlapping roles of the VA healthcare system and the criminal justice system and their inability to adequately meet the needs of veterans, particularly those with neurological, mental health, and substance abuse issues.

Wortzel et al. (2009) state that "little is also known about the frequency of TBI among incarcerated veterans; this may contribute to the unique qualities of this subpopulation of veterans as well, adding to disturbances in cognition, emotion, and behavior (impulsivity). Of note, forensic psychiatric populations feature relatively high rates of TBI, and survivors of TBI appear to face a heightened risk of suicide, which raises the disturbing possibility that there is a population of veterans incarcerated for crimes related to the cognitive and behavioral sequelae of TBIs sustained during military service and facing elevated suicide risk related to the very same service-related injury" (p. 88). The present research study hypothesizes that the same independent variables that predict incarcerated veteran suicide can be used interchangeably to predict incarcerated veteran rule violations (Wortzel et al., 2009, p. 89). Wortzel et al. (2009) are trying to emphasize that brain injury combined with substance use issues is a major contributor to the behavioral and cognitive maladjustments that occur in incarceration settings (p.89). There is limited data on veterans that have committed suicide while incarcerated, which may explain the lack of data on veterans and their rates of rule violations and attacking jail or prison staff. The overall lack of data and descriptive statistics concerning incarcerated veterans is alarming, especially considering the large influx of veterans returning from the wars in Iraq and Afghanistan that have suffered possible bodily and brain injuries. 
The interaction of brain injury, PTSD, and substance use may produce physiological reactivity in veterans that can result in the expression of angry and aggressive behaviors. Examining this interaction would be particularly useful for identifying inmates with veteran status that may be at additional risk for violating rules while incarcerated and engaging in violence. The resulting behaviors from the interaction of these variables have been known to cause isolation, diminished social bonds with friends and family, and can cause physical health issues (Taft et al., 2007, p. 498). Taft et al. (2007) describe the cluster of symptoms that characterizes PTSD, which includes hyperarousal, anger management difficulties, diminished sleep and concentration problems, and exaggerated startle response (p. 499). The researchers also describe the comorbid relationship that exists between PTSD and alcohol use in particular. Taft et al. (2007) state that PTSD symptoms often precede alcohol abuse and that the self-medicating hypothesis serves to explain the use of alcohol to minimize stress, anxiety, and hyperarousal symptoms (p. 499). The researchers report that a previous study of male veterans receiving treatment for alcohol abuse had a prevalence rate of $39 \%$ self-reported partner assault over the previous year and $20 \%$ reported severely assaulting their partner (Taft et al., 2007, p. 499). The high prevalence rates of veterans abusing alcohol and assaulting their partners allows this study to hypothesize that those inmates with veteran status and histories of alcohol abuse may be at increased risk for assaulting staff members in incarceration settings given our knowledge of alcohol related violence among veterans. Taft et al. (2007) in their research design hypothesized that alcohol was a mediator of the relationship between hyperarousal symptoms and aggression (p. 499). Similarly, this study has the potential to explore the mediating role that indicating a history of alcohol use has on the relationship between veteran status and having a history of brain injury for predicting the likelihood to violently assault staff.

Wortzel and Archiniegas (2010) discussed the possibility that combat veterans with a documented history of traumatic brain injury (TBI) and/ or PTSD at the time of their criminal offense should be treated as a different class of offenders when being sentenced by the courts, in particular, for death penalty cases (p. 412). Extant evidence (Wortzel and Archiniegas, 2010) suggests that neuropsychiatric diagnoses may in the future be treated as mitigating factors during the sentencing phase for offenders.

However, once sentenced, veterans with brain injury, psychological trauma, and/ or substance abuse issues will be mixed with the general jail or prison population. Therefore, it is important to understand through a neuro-psychiatric perspective the implications of attempting to assimilate military veterans into the general jail or prison population. Also, it is equally important to understand how incarcerated veterans with histories of brain injury, alcohol use, and substance abuse adhere to jail or prison rules while incarcerated.

\section{RESEARCH QUESTION}

We are interested in exploring whether veteran status of inmates is predictive of (1) rule violations and (2) assaults on staff. Does including variables related to substance use and brain injury into our model improve our ability to predict rule violations and assaults on staff by inmates with veteran status? 


\section{Hypotheses}

Incarcerated veterans will have higher rates of violating overall jail or prison rules compared with the general inmate population. Incarcerated veterans will have higher rates of assaulting jail or prison staff members compared with the general inmate population. Additionally, we hypothesize that the direction and magnitude of the effect between our independent and dependent variables will be statistically significantly moderated by history of alcohol use, brain injury status, and history of drug use.

\section{METHODS}

\section{Sample}

This research study will rely on data collected from the Survey of Inmates in State and Federal Correctional Facilities (SISFCF), $2004(\mathrm{~N}=14499)$. This research study is a secondary data analysis of a cross-sectional survey design focused on the prevalence of inmates with veteran status characterized as having histories of brain injury and substance use (Bureau of Justice Statistics, 2004).

This study is non-randomized and attempts to estimate the prevalence of specific risk factors that contribute to inmates with veteran status violating rules and assaulting staff while incarcerated. According to the research documentation: "A two-stage sampling procedure was used. Prisons were selected in the first stage. Inmates within sampled prisons were selected in the second stage (Bureau of Justice Statistics, 2004)."

Limitations of this design include the inability to make inferences beyond the time that the data was collected and cannot be generalized to future points in time (Sullivan, 2012). The cross-sectional design does not allow researchers to make substantive claims related to temporal relationships and prevents researchers from determining when the exposure to a risk factor occurred prior to the outcome being measured (Sullivan, 2012). The rates of non-response and missing data in large survey samples can introduce biased interpretation of results and limit generalizability.

\section{Instruments}

As the Table 1 demonstrates, 9.1\% of State and Federal prison inmates indicated that they were veterans, which is comparatively less than the estimated general population, where veterans accounted for $10.4 \%$. In the year before the offense that led to jail or prison, $40.9 \%$ of inmates reported daily or almost daily alcohol consumption, which is comparatively less than found among general population, which is estimated to have about $41.5 \%$ of individuals indicating daily or almost daily consumption of alcohol. Inmates that have suffered a stroke or brain injury make up $4.6 \%$ of the survey sample compared with the estimated general population, where these respondents accounted for about $4.4 \%$. 
Sriram Chintakrindi, Suditi Gupta: Examining Prison Rule Violations Among Incarcerated Veterans with a...

Table 1. Comparison of military service, daily alcohol use, and rates of brain injury among adult jail and prison population and the general adult population

\begin{tabular}{|l|c|c|}
\cline { 2 - 3 } \multicolumn{1}{c|}{} & State and Federal Prison Inmates & General Public \\
\hline Indicated U.S. military service & $1318(9.1 \%)$ & $110483(10.4 \%)$ \\
\hline Daily or almost daily alcohol use & $3514(40.9 \%)$ & $267299(41.5 \%)$ \\
\hline Ever had a stroke or brain injury & $664(4.6 \%)$ & $46985(4.4 \%)$ \\
\hline Average age & 35.32 & 35.29 \\
\hline
\end{tabular}

The Table 2 provides descriptive summaries by dividing inmates into two larger categories of those with veteran and non-veteran status and compares their characteristics with the estimated population by weighting the data. Inmate samples for veterans and non-veterans with brain injury and measurements of alcohol consumption are nearly identical to the estimated population. However, it should be noted that the share of incarcerated veterans that indicated that they had a history of brain injury (8.9\%) was twice as large as incarcerated non-veterans who indicated that they had a history of brain injury (4.1\%) when comparing percentages.

Table 2. Comparison of surveyed veterans versus non-veteran status on brain injury and alcohol consumption in the state and federal prisons and the general adult population

\begin{tabular}{|l|c|c|}
\cline { 2 - 3 } \multicolumn{1}{l|}{} & $\begin{array}{c}\text { State and Federal Prison } \\
\text { Inmates }\end{array}$ & General Public \\
\hline Veterans & & $9869(9.0 \%)$ \\
\hline Yes, brain injury & $117(8.9 \%)$ & $99583(90.0 \%)$ \\
\hline No brain injury & $1189(91.0 \%)$ & $29559(43.8 \%)$ \\
\hline Daily or almost daily alcohol use & $349(43.5 \%)$ & $37879(56.1 \%)$ \\
\hline Less than once a week alcohol use & $453(56.4 \%)$ & $24510(30.1 \%)$ \\
\hline Yes, experienced drug withdrawal, year before admission & $296(30.5 \%)$ & $56809(69.8 \%)$ \\
\hline No, did not experience drug withdrawal, year before admission & $674(69.4 \%)$ & \\
\hline Non-Veterans & & $37029(3.9 \%)$ \\
\hline Yes, brain injury & $546(4.1 \%)$ & $904454(96.0 \%)$ \\
\hline No brain injury & $12457(95.8 \%)$ & $237569(41.2 \%)$ \\
\hline Daily or almost daily alcohol use & $3163(40.6 \%)$ & $338381(58.7 \%)$ \\
\hline Less than once a week alcohol use & $4621(59.3 \%)$ & $239754(30.3 \%)$ \\
\hline Yes, experienced drug withdrawal, year before admission & $3505(32.2 \%)$ & $550394(69.6 \%)$ \\
\hline No, did not experience drug withdrawal, year before admission & $7378(67.7 \%)$ & \\
\hline
\end{tabular}

\section{Procedure and Plan of Analysis}

The Table 3 provides descriptive summaries of veterans and non-veterans and their adherence to overall prison rules and their capacity for physically assaulting staff. Given the larger proportion of non-veterans in the survey sample, it is difficult to discuss any relationships between veterans and their capacity to violate prison rules or assault staff based on the characteristics of having history of brain injury or alcohol abuse. Therefore, in order to establish robust relationships between the risk-factors of veteran status, brain injury, and alcohol abuse predicting rule violations while incarcerated, statistical tests Pearson Chi-square and binary logistic regression will be used in the research design. 
Table 3. Comparison of surveyed veterans versus non-veteran status on being found guilty of violating any rules and physically assaulting staff members in the state and federal prisons

\begin{tabular}{|l|c|}
\cline { 2 - 2 } \multicolumn{1}{l|}{} & State and Federal Prison Inmates \\
\hline Veterans & \\
\hline Yes, found guilty of violating any rules & $617(47.4 \%)$ \\
\hline Not found guilty of violating any rules & $683(52.5 \%)$ \\
\hline Yes, found guilty of physically assaulting staff member & $26(4.2 \%)$ \\
\hline Not found guilty of physically assaulting staff member & $591(95.7 \%)$ \\
\hline Non-Veterans & \\
\hline Yes, found guilty of violating any rules & $6597(50.9 \%)$ \\
\hline Not found guilty of violating any rules & $6341(49.0 \%)$ \\
\hline Yes, found guilty of physically assaulting staff member & $383(5.8 \%)$ \\
\hline Not found guilty of physically assaulting staff member & $6208(94.1 \%)$ \\
\hline
\end{tabular}

The independent variables that will be dummy-coded and tested are veteran status, brain injury status, drug use, and alcohol abuse status. For the logistic regression analysis, a filter will be created to filter-out non-veterans for predicting traits only for individuals who have indicated veteran status. The dependent variable for the first logistic regression test is "found guilty of violating any rules" while incarcerated, which will be dummy-coded: yes or no. The dependent variable for the second logistic regression test is "found guilty of physically assaulting staff member" while incarcerated, which will be dummy-coded: yes or no.

The Table 4 presents the percent of cases with missing data in the independent and dependent variables for individuals that indicated veteran status. The share of cases with missing data for the independent variables: Alcohol Use and Drug Use, and the dependent variable: Written up or found guilty of assaulting staff members, ranged from $26 \%$ to $53 \%$. The substantial amount of missing data required imputation. Missing data for variables brain injury status, drug use status, alcohol use status, and the dependent variables was handled through a simple imputation that involved setting all missing data as a default term. For example, if brain injury status was listed as missing, the data was transformed by default to indicate that the individual had no brain injury. However, individuals who did not indicate veteran or non-veteran status were not included in the present analysis and the researcher did not attempt to impute data for the veteran status variable. The imputation of missing data was required for the logistic regression or else the analysis would have resulted in a casewise deletion of a large number of cases. 
Sriram Chintakrindi, Suditi Gupta: Examining Prison Rule Violations Among Incarcerated Veterans with a...

Table 4. Missing data analysis of filtered cases that indicated veteran status

\begin{tabular}{|c|c|c|c|c|}
\hline Variables & $\begin{array}{c}\text { Number of } \\
\text { Available } \\
\text { Cases with } \\
\text { Data }\end{array}$ & $\begin{array}{l}\text { Number of } \\
\text { Cases with } \\
\text { Missing Data }\end{array}$ & Total & $\begin{array}{l}\text { Percent of } \\
\text { Cases with } \\
\text { Missing Data }\end{array}$ \\
\hline \multicolumn{5}{|l|}{ Independent Variables } \\
\hline $\begin{array}{l}\text { Alcohol Use (daily or almost daily alcohol use or once a } \\
\text { week or less) }\end{array}$ & 802 & 516 & 1318 & $39 \%$ \\
\hline Drug Use (Experienced withdrawal: yes or no) & 970 & 348 & 1318 & $26 \%$ \\
\hline Brain Injury (Ever had a stroke or brain injury: yes or no) & 1306 & 12 & 1318 & $1 \%$ \\
\hline \multicolumn{5}{|l|}{ Dependent Variables } \\
\hline Written up or found guilty of breaking any rules (yes or no) & 1300 & 18 & 1318 & $1 \%$ \\
\hline $\begin{array}{l}\text { Written up or found guilty of assaulting staff members (yes } \\
\text { or no) }\end{array}$ & 617 & 701 & 1318 & $53 \%$ \\
\hline
\end{tabular}

\section{RESULTS}

According to the Chi-Square statistic listed at the bottom of the Table 5, the frequency of the distribution of those guilty of rule breaking in jail or prison (outcome) is not independent of veteran status (exposure). Therefore, we can reject the null hypothesis because there is a statistically significant relationship between being found guilty of rule breaking and veteran status $(p=0.015)$.

Table 5. SISFCF2004 survey respondents' veteran status by ruling breaking

\begin{tabular}{|c|c|c|}
\hline & Survey Respondents (N) & Percentage \\
\hline \multicolumn{3}{|l|}{ Veterans } \\
\hline Found guilty of breaking any rules & 617 & $47 \%$ \\
\hline Not found guilty of breaking any rules & 683 & $53 \%$ \\
\hline \multicolumn{3}{|l|}{ Non-veterans } \\
\hline Found guilty of breaking any rules & 6597 & $51 \%$ \\
\hline Not found guilty of breaking any rules & 6341 & $49 \%$ \\
\hline \multicolumn{3}{|l|}{ Pearson Chi-Square $(1)=5.882, p=0.015$} \\
\hline
\end{tabular}

According to the Chi-Square statistic listed at the bottom of the Table 6, the frequency of the distribution of those guilty of assaulting staff (outcome) is independent of veteran status (exposure). Therefore, we can fail to reject the null hypothesis because there is not a statistically significant relationship between being found guilty of assaulting jail or prison staff and veteran status ( $p=0.101)$. However, a confounding or spurious statistical association may exist because we have not controlled for confounding variables such as alcohol use status, drug use status, or brain injury status. 
Table 6. SISFCF2004 survey respondents' veteran status by assaulting staff

\begin{tabular}{|c|c|c|}
\hline & & \\
\hline & Survey Respondents (N) & Percentage \\
\hline \multicolumn{3}{|l|}{ Veterans } \\
\hline Found guilty of assaulting staff & 26 & $4 \%$ \\
\hline Not found guilty of assaulting staff & 591 & $96 \%$ \\
\hline \multicolumn{3}{|l|}{ Non-veterans } \\
\hline Found guilty of assaulting staff & 383 & $6 \%$ \\
\hline Not found guilty of assaulting staff & 6208 & $94 \%$ \\
\hline \multicolumn{3}{|c|}{ Pearson Chi-Square $(1)=2.688, p=0.101$} \\
\hline
\end{tabular}

In this research study, we conducted four logistic regressions for each of the two dependent variables: violating any prison rules and assaulting jail or prison staff members. The first logistic regression that was conducted took in consideration the dependent variable violating any rules while incarcerated, as presented in the Table 7. Only those individuals who had reported veteran status were analyzed in the first logistic regression. In order to test for the significance of including the independent variables alcohol use, drug use, and brain injury status as predictors, we observed that the -2 LL was 1806.182. Including the independent variables into our model improved our ability to predict the odds of violating any rules while incarcerated because the $-2 \mathrm{LL}$ was lower in the full model and the related chi-square was statistically significant (chi-square of $15.597, p=0.001$ ). Thus, we have significantly improved our ability to predict violating rules while incarcerated through the introduction of the independent variables.

Table 7. Logistic regression for predicting veterans violating any rules while incarcerated

\begin{tabular}{|l|c|c|c|c|}
\cline { 2 - 4 } \multicolumn{1}{c|}{} & B & Wald & p-value & odds-ratio \\
\hline Constant & -0.257 & 14.462 & 0.000 & 0.760 \\
\hline Alcohol Use (1 = yes) & 0.454 & 12.839 & 0.000 & 1.575 \\
\hline Drug Use (1 = yes) & -0.100 & 0.006 & 0.941 & 0.990 \\
\hline Brain Injury (1 = yes) & 0.325 & 2.763 & 0.096 & 1.384 \\
\hline
\end{tabular}

$(-2 \mathrm{LL}=1806.182$, Chi-Square $=15.597, \mathrm{p}=.001$, Cox and Snell R square $=0.012$, Nagelkerke $\mathrm{R}$ square $=0.016)$

Since the model in the Table 7 is statistically significant, we are interested in examining which individual relationships are significant and interpreting them by using the odds ratios. We found that drug use did not significantly predict violations of rules while incarcerated (Wald $=12.839$, $p=0.941)$. We also found that brain injury status did not significantly predict violations of rules while incarcerated (Wald $=2.763, p=0.096$ ). However, alcohol use did statistically significantly predict violations of rules while incarcerated (Wald $=12.839, p<0.001$ ). For alcohol use we interpret this odds ratio as veterans who drank alcohol daily or almost daily prior to incarceration are 1.575 times as likely as veterans who drank less than once a week prior to incarceration to violate prison rules while incarcerated. Veterans who drank alcohol daily or almost daily prior to incarceration are about 57 percent more likely than veterans who drank alcohol less than once a week prior to incarceration to violate rules while incarcerated.

The second logistic regression that was conducted took in consideration the dependent variable assaulting jail or prison staff while incarcerated, as presented in the Table 8. Only those individuals who had reported veteran status were analyzed in the the second logistic regression. In order to test for the significance of including the independent variables alcohol use, drug use, 
and brain injury status as predictors, we observed that the $-2 \mathrm{LL}$ was 252.996. Including the independent variables into our model did not improve our ability to predict the odds of assaulting jail or prison staff while incarcerated because the $-2 \mathrm{LL}$ was higher in the full model and the related chi-square was not statistically significant (chi-square of $2.628, p=0.453$ ). Thus, we have not significantly improved our ability to predict assaulting jail or prison staff while incarcerated through the introduction of the independent variables.

Table 8. Logistic regression for predicting veterans assaulting jail or prison staff while incarcerated

\begin{tabular}{|l|c|c|c|c|}
\cline { 2 - 4 } \multicolumn{1}{c|}{} & B & Wald & p-value & odds-ratio \\
\hline Constant & -4.057 & 221.926 & 0.000 & 0.170 \\
\hline Alcohol Use (1=yes) & -0.270 & 0.323 & 0.570 & 0.764 \\
\hline Drug Use (1=yes) & 0.658 & 2.432 & 0.119 & 1.930 \\
\hline Brain Injury (1=yes) & 0.323 & 0.270 & 0.604 & 1.382 \\
\hline
\end{tabular}

$(-2 \mathrm{LL}=252.996, \mathrm{Chi}$-Square $=2.628, \mathrm{p}=.453, \mathrm{Cox}$ and Snell R square $=0.002$, Nagelkerke $\mathrm{R}$ square $=0.011)$

The third logistic regression that was conducted took in consideration the dependent variable violating rules while incarcerated, as presented in the Table 9. Both veterans and non-veterans were analyzed in the third logistic regression. In order to test for the significance of including the independent variables veteran status, alcohol use, drug use, and brain injury status as predictors, we observed that the -2 LL was 19988.426. Including the independent variables into our model improved our ability to predict the odds of violating any rules while incarcerated because the -2 LL was higher in the full model and the related chi-square was statistically significant (chi-square of $89.067, p<.001$ ). Thus, we have significantly improved our ability to predict violating any rules while incarcerated through the introduction of the independent variables.

Table 9. Logistic regression for predicting individuals incarcerated violating any rules while incarcerated

\begin{tabular}{|l|c|c|c|c|}
\cline { 2 - 4 } \multicolumn{1}{c|}{} & B & Wald & p-value & odds-ratio \\
\hline Constant & -0.096 & 19.058 & 0.000 & 0.909 \\
\hline Veteran Status (1=yes) & -0.149 & 6.589 & 0.010 & 0.861 \\
\hline Alcohol Use (1 =yes) & 0.329 & 69.449 & 0.000 & 1.389 \\
\hline Drug Use (1=yes) & 0.046 & 1.422 & 0.233 & 1.047 \\
\hline Brain Injury (1=yes) & 0.221 & 7.536 & 0.006 & 1.247 \\
\hline
\end{tabular}

$(-2 \mathrm{LL}=19988.426$, Chi-Square $=89.067, \mathrm{p}=.000, \mathrm{Cox}$ and Snell R square $=.006$, Nagelkerke $\mathrm{R}$ square $=.008)$

Since the model in the Table 9 is statistically significant, we are interested in examining which individual relationships are significant and interpreting them by using the odds ratios. We found that drug use did not significantly predict violations of rules while incarcerated (Wald $=1.422$, $p=0.233$ ). However, veteran status did statistically significantly predict violations of rules while incarcerated (Wald $=6.589, p=0.01$ ). For veterans status we interpret this odds ratio as incarcerated individuals who indicated veteran status as being .861 times less likely than non-veterans to violate any rules while incarcerated. Incarcerated individuals who indicated veteran status are 13.9 percent less likely to violate rules while incarcerated compared with individuals who indicated non-veteran status. Alcohol use did statistically significantly predict violations of rules while incarcerated (Wald $=69.449, p<0.001$ ). For alcohol use we interpret this odds ratio as incarcerated individuals who 
drank alcohol daily or almost daily prior to incarceration are 1.389 times as likely as incarcerated individuals who drank less than once a week prior to incarceration to violate prison rules while incarcerated. Incarcerated individuals who drank alcohol daily or almost daily prior to incarceration are about 38.9 percent more likely than incarcerated individuals who drank alcohol less than once a week prior to incarceration to violate rules while incarcerated. Brain injury status did statistically significantly predict violations of rules while incarcerated (Wald $=7.536, p=0.006$ ). For brain injury status we interpret this odds ratio as incarcerated individuals who indicated having a brain injury are 1.247 times as likely as incarcerated individuals who did not indicate having a brain injury to violate rules while incarcerated.

The fourth logistic regression that was conducted took in consideration the dependent variable assaulting jail or prison staff while incarcerated, as presented in the Table 10. Both veterans and non-veterans were analyzed in the fourth logistic regression. In order to test for the significance of including the independent variables veteran status, alcohol use, drug use, and brain injury status as predictors, we observed that the $-2 \mathrm{LL}$ was 3714.452 . Including the independent variables into our model improved our ability to predict the odds of violating any rules while incarcerated because the $-2 \mathrm{LL}$ was higher in the full model and the related chi-square was statistically significant (chisquare of $9.706, p=0.046$ ). Thus, we have significantly improved our ability to predict assaulting jail or prison staff while incarcerated through the introduction of the independent variables.

Table 10. Logistic regression for predicting individuals incarcerated assaulting jail or prison staff while incarcerated

\begin{tabular}{|l|c|c|c|c|}
\cline { 2 - 4 } \multicolumn{1}{c|}{} & B & Wald & p-value & odds-ratio \\
\hline Constant & -3.567 & 2869.531 & 0.000 & 0.028 \\
\hline Veteran Status (1=yes) & -0.425 & 4.278 & 0.039 & 0.654 \\
\hline Alcohol Use (1=yes) & 0.173 & 2.301 & 0.129 & 1.189 \\
\hline Drug Use (1=yes) & -0.015 & 0.018 & 0.893 & 0.985 \\
\hline Brain Injury (1=yes) & 0.389 & 3.521 & 0.061 & 1.476 \\
\hline
\end{tabular}

$(-2 \mathrm{LL}=3714.452$, Chi-Square $=9.706, \mathrm{p}=.046, \mathrm{Cox}$ and Snell $\mathrm{R}$ square $=.001$, Nagelkerke $\mathrm{R}$ square $=.003)$

Since the model in the Table 10 is statistically significant, we are interested in examining which individual relationships are significant and interpreting them by using the odds ratios. We found that alcohol use (Wald=2.301, $\mathrm{p}=.129)$, drug use (Wald=.018, $p=0.893)$, and brain injury status (Wald $=3.521, p=0.061$ ) did not statistically significantly predict assaulting jail or prison staff while incarcerated. However, veteran status did statistically significantly predict assaulting jail or prison staff while incarcerated (Wald $=4.278, p=0.039$ ). For veteran status we interpret this odds ratio as incarcerated individuals who indicated veteran status as being .654 times less likely than non-veterans to assault jail or prison staff while incarcerated. Incarcerated individuals who indicated veteran status are 34.6 percent less likely to assault jail or prison staff while incarcerated compared with individuals who indicated non-veteran status. 


\section{DISCUSSION}

The present research study confirmed a number of the specified hypotheses for the logistic regression models that were conducted in the present analysis. Daily or almost daily consumption of alcohol in the year prior to incarceration was a significant predictor for violating any rules while incarcerated (Tables 7 and 9). The symmetry between the present research findings and what has been presented by previous research studies (Taft et al, 2007; IOM and DOD, 2012) indicates that alcohol use is a significant risk factor for criminal behavior and rule violations while incarcerated. Experts dealing with veterans and incarcerated population should continue developing treatments and prevention methods for alcoholism as a public health and safety measure. With regards to veterans in particular, combating the culture of alcohol consumption should become a priority within the military hierarchy. The results in the present study indicate that daily or almost daily alcohol use is a predictor of rule violations while incarcerated. However, if we think of rules violations in alternative domains that require conformity and adherence to discipline, we immediately think of military service, where soldiers are operating technologically sophisticated and often times lethal weaponry that can inflict massive harm if mishandled. Therefore, any ingestible substance that may increase risk of violating rules should be immediately targeted and banned. This research study is not only a lesson on the dangers of alcohol for increasing risk for rule violations while incarcerated, it may, more generally, also apply to risk for rule violations in settings that demand complete discipline, conformity, and deference to authority. The present research study recommends that the military adopt a culture of abstinence towards alcohol similar to how illicit drug use is treated. A zero-tolerance policy towards alcohol for the military will save lives, decrease risk for rule violations, and will increase the overall public health of our communities.

However, it should be noted that in the Table 9, veteran status did predict decreased risk for violating jail or prison rules compared with non-veterans. However, this finding should be carefully interpreted due to the lack of data and in relation to sample size differences between veterans and non-veterans. However, the counter-intuitive finding that veterans are at lower risk for rule violations while incarcerated compared with non-veterans may be a result of veterans receiving highly regimented training and discipline. Also, the present research study did not control for crime types. It may be that veterans commit lower-level types of crimes and are not in contact with the system long enough to engage in serious rule violations while incarcerated compared with non-veterans. Researchers should be reminded that the imputation method used in this research study may have led to severely biased and skewed results and should be interpreted with caution.

Previous research (Taft et al, 2007; Wortzel et al., 2010) demonstrates the negative effects that suffering a brain injury has on an individual's daily functioning. Even routines that once occurred seamlessly for individuals, such as taking care of sanitary needs, holding a job, paying bills, and maintaining relationships with friends and family can become disrupted and difficult to complete following a brain injury. This research study demonstrates that the relationship between having a history of brain injury and rule violations needs to be studied in more detail.

The study did not control for severity of brain injury, type of diagnosis for brain injury, and the dosage of brain injury treatment from medical professionals prior to or during the period of incarceration that resulted in rule violations while incarcerated. Brain injury etiology can include 
accidents, combat, disease, pollution, drug and alcohol consumption, genetic heritability, and prenatal exposure to toxins. Physical aspects of brain injury are not manifest and require medical expertise to be diagnosed. However, the cognitive and behavioral effects of brain injury are observable (Taft et al., 2007). Concentration difficulties, hyperarousal, disinhibited behaviors, and anger management issues may be misdiagnosed as psychiatric issues, when in fact the cause of these symptoms may be related to a single event or multiple head injuries accumulated over the course of a military career.

Therefore, it is important not only to address the issue of brain injury in the military and prison institutions, it is also important for researchers to develop evidence based practices that focus on treating and rehabilitating individuals suffering from mild to severe brain injuries. Although it is difficult to separate psychiatric from neurological conditions, it is imperative that researchers and practitioners stop relying on umbrella definitions such as post-traumatic stress disorder (PTSD) or traumatic brain injury (TBI). On the other hand, these terms have helped researchers and practitioners to advance theoretical understanding of the neurological correlates of behavior. It is essential that researchers and practitioners develop more concrete diagnostic criteria that can reliably identify which regions or pathways within the brain have been affected or damaged in order to develop individualized treatment options for individuals with brain injury.

\section{LIMITATIONS}

There was a substantial amount of missing data in the predictor and outcome variables and the researcher was unable to run any of the imputation methods such as EM algorithm or Multiple Imputation. The imputation method used in the present research study lacked any theoretical and conceptual justification. This method was conducted for convenience, due to lack of knowledge about imputation, and a lack of resources to conduct EM algorithm or multiple imputation. Therefore, the findings from this study should be interpreted with extreme caution and replicated with a more theoretical and conceptually sound imputation method in future research. The logistic regression models did not control for static risk characteristics such as age, gender, race, education level, and socio-economic status. In addition, the logistic regression models did not test for interaction, mediation, and moderation relationships among the variables either.

\section{FUTURE RESEARCH}

The logistic regression models might be improved if the researcher applied a theoretically specified model, such as low self-control (Gottfredson and Hirschi, 1990), negative peer associations (Akers, 1996) or social bonds (Hirschi, 1969), that is able to examine latent factors at individual level that may mediate the relationship between the predictor variables: alcohol, drug use, and brain injury, and the outcome variables: prison rule violations and assaulting staff. 


\section{POLICY IMPLICATIONS}

Due to the large influx of veterans returning from wars abroad, researchers such as Wortzel and Archiniegas (2010) discuss the possibility that combat veterans with a documented history of traumatic brain injury (TBI) and/ or post-traumatic stress disorder (PTSD) at the time of their criminal offense should be treated as a different class of offenders when being sentenced by the courts, in particular, for death penalty cases (p. 412). Extant evidence (Wortzel and Archiniegas, 2010) suggests that, in the future, neuropsychiatric diagnoses may be treated as mitigating factors during the sentencing phase for offenders. Therefore, researchers should continue to focus on identifying the static and dynamic risk factors that place veterans at risk of engaging in illegal behaviors, rule violations, and violence inside and outside of penal settings.

\section{ETHICAL CONSIDERATIONS}

The Institutional Review Board at California State University, Stanislaus, designates this study as exempt from review because it uses secondary data publicly available from the Inter-university Consortium for Political and Social Research (ICPSR). All identifying information about participants in this study is unavailable or deidentified in the publicly available datasets.

\section{REFERENCES}

Akers, R. L., \& Lee, G. (1996). A longitudinal test of social learning theory: Adolescent smoking. Journal of drug issues, 26(2), 317-343.

Black, D. W. (2005). Incarceration and Veterans of the First Gulf War. Military Medicine, 170(7), 612-618.

Coté, I., Heintzman, M., Glancy, G. D., Dufour, M., Hardy, K., \& Ward, H. (2020). Veterans behind bars: Examining criminogenic risk factors of Veteran incarceration. Journal of Military, Veteran, and Family Health, 6(3), 21-30.

Davis, T. M., Baer, J. S., Saxon, A. J., \& Kivlahan, D. R. (2003). Brief motivational feedback improves post-incarceration treatment contact among veterans with substance use disorders. Drug and Alcohol Dependence, 69, 197-203.

Gottfredson, M. R., \& Hirschi, T. (1990). A general theory of crime. Stanford University Press.

Greenberg, G. A., \& Rosenheck, R. A. (2009). Mental Health and Other Risk Factors for Jail Incarceration Among Male Veterans. Psychiatric Quarterly, 80(1), 41-53.

Greenberg, G. A., \& Rosenheck, R. A. (2011). Incarceration Among Male Veterans: Relative Risk of Imprisonment and Differences Between Veteran and Nonveteran Inmates. International Journal of Offender Therapy and Comparative Criminology, 56(4), 646-667.

Hirschi, T. (1969). A control theory of delinquency. Criminology theory: Selected classic readings, 1969, 289-305.

Institute of Medicine of the National Academies and the Department of Defense (2012). Substance Use Disorders in the U.S. Armed Forces. Washington, DC: National Academies Press. 
Logan, M. W., McNeeley, S., \& Morgan, M. A. (2021a). The effects of traumatic brain injury and post-traumatic stress disorder on prison adjustment and recidivism among military veterans: evidence from Minnesota. Psychiatric quarterly, 1-12.

Logan, M. W., McNeeley, S., \& Morgan, M. A. (2021b). Not-so-special forces? Revisiting the "veteran effect" in the context of prison research. Journal of Criminal Justice, 72, 101762.

Moses, M. C. (2009). Do Ask, Do Tell: An Examination of Veterans Behind Bars. Corrections Compendium, Winter, 9-12.

Russell, R. T. (2009). Veterans Treatment Court: A Proactive Approach. Criminal and Civil Confinement, 35, 357-371.

Saxon, A. J., Davis, T. M., Sloan, K. L., McKnight, K. M., McFall, M. E., \& Kivlahan, D. R. (2001). Trauma, Symptoms of Posttraumatic Stress Disorder, and Associated Problems Among Incarcerated Veterans. Psychiatric Services, 52(7), 959-964.

Sullivan, L. M. (2012). Essentials of Biostatistics in Public Health: Second Edition. Boston, MA: Jones and Bartlett Learning.

Taft, C. T., Kaloupek, D. G., Schumm, J. A., Marshall, A. D., Panuzio, J., King, D. W., \& Keane, T. M. (2007). Posttraumatic Stress Disorder Symptoms, Physiological Reactivity, Alcohol Problems, and Aggression Among Military Veterans. Journal of Abnormal Psychology, 116(3), 498-507.

United States. Bureau of Justice Statistics. Survey of Inmates in State and Federal Correctional Facilities, [United States], 2004. Inter-university Consortium for Political and Social Research [distributor], 2019-12-12. https://doi.org/10.3886/ICPSR04572.v6

Wortzel, H. S., \& Arciniegas, D. B. (2010). Combat Veterans and the Death Penalty: A Forensic Neuropsychiatric Perspective. The Journal of the American Academy of Psychiatry and the Law, 38, 407-414.

Wortzel, H. S., Binswanger, I. A., Anderson, C. A., \& Adler, L. E. (2009). Suicide Among Incarcerated Veterans. The Journal of the American Academy of Psychiatry and the Law, 37, 82-91. 


\title{
KRŠENJE ZATVORSKIH PRAVILA MEĐU ZATVORENIM VETERANIMA S POVIJESTI OZLJEDE MOZGA, KONZUMACIJE ALKOHOLA I ZLOUPORABE OPOJNIH SREDSTAVA
}

\author{
Sriram Chintakrindi \\ California State University, Stanislaus \\ Suditi Gupta \\ California State University, Stanislaus, Modesto Junior College
}

\begin{abstract}
SAŽETAK
Kontekst: Ispitati na koji način nezavisne varijable: veteranski status, ozljeda mozga, zlouporaba droga i konzumacija alkohola predviđaju kršenje pravila i napade na zatvorsko osoblje tijekom izvršavanja zatvorske kazne. $U$ istraživanju se koriste agregirani i disagregirani podaci kako bi se prikazala povezanost između izloženosti i ishoda.

Metode: Presječeni podaci prikupljeni su iz Ankete zatvorenika u državnim i saveznim penalnim ustanovama (SISFCF) iz 2004. ( $n=14499)$. Korišteni su hi-kvadrat test, Cochran-Mantel-Haenszelov $(C M H)$ test i logistička regresija kako bi se odredio relativan doprinos nezavisnih varijabli u predviđanju kršenja pravila i napada na zatvorsko osoblje tijekom izvršavanja zatvorske kazne. $\mathrm{U}$ istraživanju su ispitane određene hipoteze navedene u pripadajućem odjeljku ovog rada.

Rezultati: Nalazi logističke regresije koja je provedena u istraživanju upućuju na značajnu povezanost između veteranskog statusa, konzumacije alkohola i povijesti ozljede mozga s jedne strane, te zavisne varijable „okrivljen ili prijavljen za kršenje zatvorskih pravila tijekom izvršavanja zatvorske kazne"s druge strane.

Zaključak: Konzumacija alkohola i ozljeda mozga mogu ozbiljno ugroziti zdravlje i sigurnost zatvorenih veterana i ostalih zatvorenika. Svakodnevna ili gotovo svakodnevna konzumacija alkohola najsnažniji je prediktor kršenja zatvorskih pravila. Iz tog razloga, znanstvenici i službene osobe u zatvorskom sustavu trebaju i dalje razvijati intervencije i politike za smanjenje konzumacije alkohola kod osoba koje su u kontaktu s kaznenopravnim sustavom.
\end{abstract}

Ključne riječi: veteranski status, ozljeda mozga, zlouporaba opojnih sredstava 